\title{
A importância da ordem Ciconiiformes na cadeia epidemiológica de Salmonella spp. para a saúde pública e a conservação da diversidade biológica ${ }^{1}$
}

\begin{abstract}
Marcio A. Silva ${ }^{2,3^{*}}$, Maria F.V. Marvulo ${ }^{2}$, Rinaldo A. Mota ${ }^{3}$ e Jean C.R. Silva ${ }^{2,3}$
ABSTRACT.- Silva M.A., Marvulo M.F.V., Mota R.A. \& Silva J.C.R. 2010. [The role of order Ciconiiformes in the epidemiological chain of Salmonella spp. for public health and biological diversity conservation.] A importância da ordem Ciconiiformes na cadeia epidemiológica de Salmonella spp. para a saúde pública e a conservação da diversidade biológica. Pesquisa Veterinária Brasileira 30(7):573-580. Laboratório de Doenças Infecciosas, Departamento de Medicina Veterinária, Universidade Federal Rural de Pernambuco, Rua Dom Manoel de Medeiros s/n, Dois Irmãos, Recife, PE 52171-900, Brazil. E-mail: marcioandre_mv@ hotmail.com

Biological diversity is represented by all nature units and its conservation is about the survival of human beings. Infectious diseases are one of the possible threats for wildlife conservation, which includes salmonellosis as a most important disease, especially for the avifauna. Top alimentary chain birds such as Ciconiiformes can be reservoirs and disseminators of Salmonella spp. to other wild and domestic animals, and also for human populations, with serious risks to public and environmental health. This review describes infection by Salmonella spp., its etiological agent and occurrence in Ciconiiformes, as well as the importance of these wild birds for the epidemiological chain of the zoonosis, and discusses the risks for public health and biological diversity conservation.
\end{abstract}

INDEX TERMS: Salmonellosis, wild birds, conservation medicine.

RESUMO.- A diversidade biológica é representada por todas as unidades da natureza e sua conservação diz respeito à sobrevivência da própria espécie humana. Uma das ameaças à sua conservação são as doenças infecciosas que afetam a fauna, dentre as quais se podee incluir a salmonelose como uma das mais importantes, especialmente para a avifauna. Aves de topo de cadeia alimentar como os Ciconiiformes podem ser potenciais reservatórios e disseminadores da Salmonella spp. para outras espécies silvestres e também para populações humanas e animais domésticos, podendo causar prejuízos à saúde pública e ao meio ambiente. Objetivou-se descrever a infecção ou doença por Salmonella sp., o seu agente etiológico

\footnotetext{
${ }^{1}$ Recebido em 25 de junho de 2010.

Aceito para publicação em 10 de julho de 2010.

2 Instituto Brasileiro para Medicina da Conservação - Tríade, Rua Silveira Lobo 32, Cx. Postal 48, Casa Forte, Recife, PE 52061-030, Brasil. *Autor para correspondência: marcioandre_mv@ hotmail.com

${ }^{3}$ Laboratório de Doenças Infecciosas, Departamento de Medicina Veterinária (DMV), Universidade Federal Rural de Pernambuco (UFRPE), Rua Dom Manoel de Medeiros s/n, Dois Irmãos, Recife, PE 52171-900.
}

e sua ocorrência em Ciconiiformes, bem como demonstrar a importância destas aves na cadeia epidemiológica silvestre desta zoonose, verificando os riscos para a saúde pública e para a conservação da diversidade biológica.

TERMOS DE INDEXAÇÃO: Salmoneloses, aves silvestres, medicina da conservação.

\section{INTRODUÇÃO}

A diversidade biológica é representada pelas unidades da natureza e compreendem plantas, microorganismos e animais dos mais diversos tipos, incluindo o ser humano. Sua conservação é uma das preocupações mundiais mais atuais, devido a diversos fatores desde estéticos e espirituais, até políticos, financeiros e por questão de sobrevivência da própria espécie humana (Andriolo 2006). Algumas das principais ameaças à manutenção da diversidade biológica são a extinção e a vulnerabilidade de espécies, fragmentação e perda de habitats, poluição ambiental, aumento da população humana e da exploração de recursos naturais, introdução de espécies exóticas e dispersão de doenças (Andriolo 2006), destacando-se as enfermidades 
infecciosas (Hernandez-Divers et al. 2006, Newman et al. 2007), como as salmoneloses, uma zoonose de grande significância, tanto para a saúde pública, quanto para a saúde animal, geralmente estando associada a processos entéricos e/ou septicêmicos (Carvalho 2006). É causada por bactérias do gênero Salmonella spp., pertencentes à família Enterobacteriaceae, tendo como reservatórios répteis, aves e mamíferos, inclusive o homem (Fortuna \& Franco 2005, Carvalho 2006, Tessari et al. 2008). Essa enfermidade causa grandes perdas econômicas em criações animais (Tessari et al. 2008), podendo também causar prejuízos a populações de animais silvestres (Pennycott et al. 2006, Newman et al. 2007).

As aves silvestres da Ordem Ciconiiformes estão no topo da cadeia alimentar de ambientes aquáticos. Em alguns casos podem tornar-se aves sinantrópicas podendo ser reservatórias e disseminadoras de Salmonella spp. e também vulneráveis a todos os tipos de poluentes provenientes de atividades humanas (Fontenelle 2006). Estu- dos demonstrando sua importância na epidemiologia das salmoneloses são escassos. Sendo assim, objetivou-se realizar uma revisão de literatura envolvendo a descrição da importância de aves Ciconiiformes na cadeia epidemiológica de Salmonella spp., verificando sua relação com a saúde pública e a conservação da diversidade biológica.

\section{ORDEM CICONIIFORMES}

No Brasil, a Ordem dos Ciconiiformes compreende as famílias Ardeidae (garças e socós), Ciconidae (jaburu, maguari, cabeça-seca e cegonhas), Threskiornithidae (curicaca, corocoró, guará, colhereiro e afins), Cochleariidae (arapapás) e Cathartidae (urubus e condor) (Sick 2001, Fontenelle 2006). As espécies de aves Ciconiiformes brasileiras estão descritas no Quadro 1 (Sick 2001).

Estas aves Ciconiiformes são carnívoras e insetívoras, constituindo sua dieta de peixes, moluscos, insetos, crustáceos, anfíbios e répteis. Algumas espécies também são onívoras. Costumam nidificar em colônias ou ninhais, cons-

Quadro 1. Espécies de aves silvestres da ordem Ciconiiformes do Brasil

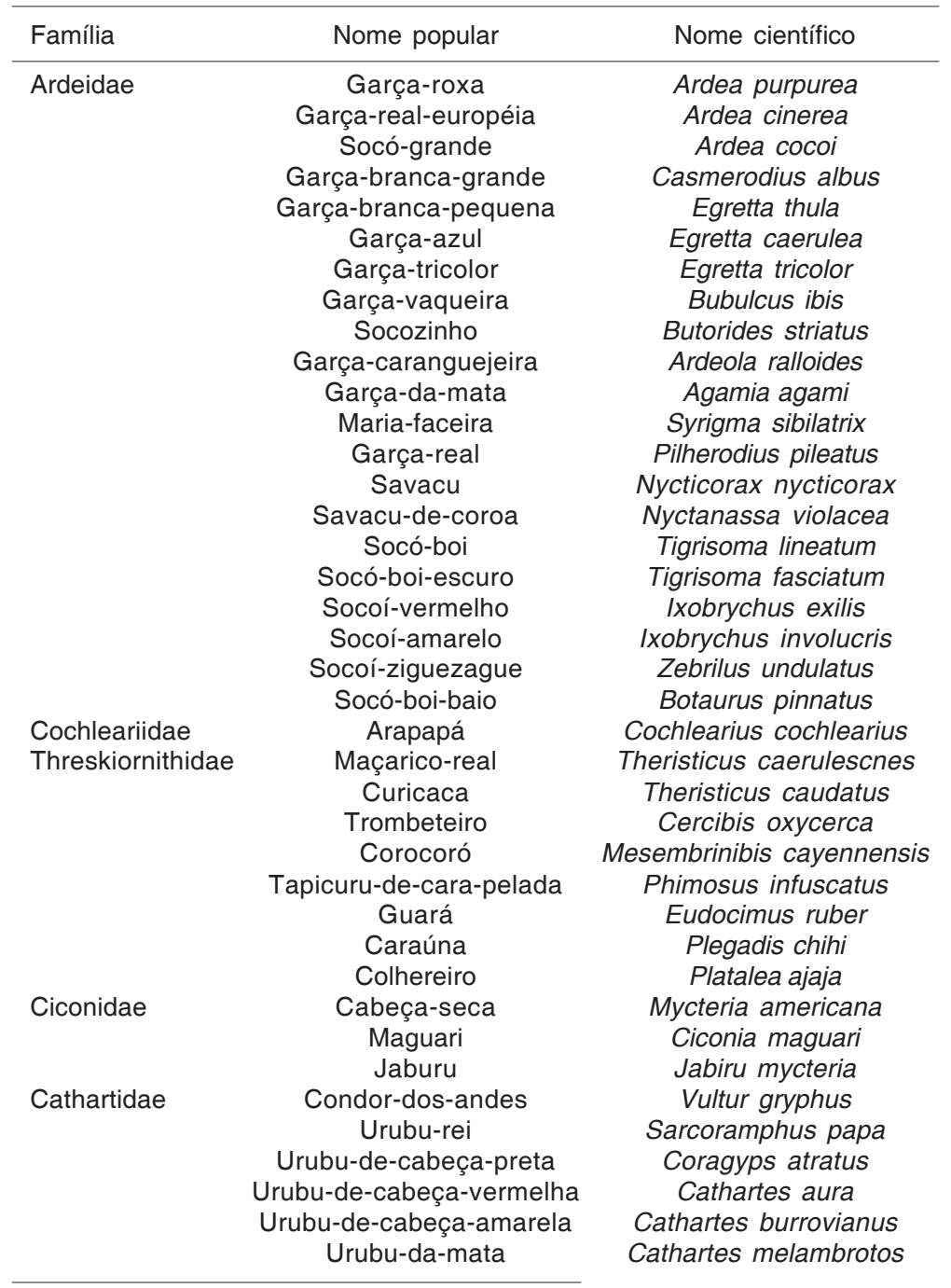

Fonte: Sick (2001). 
tituídos por diversas espécies, com exceção dos jaburus e dos maguaris. Normalmente têm hábitos diurnos e crepusculares, e não possuem dimorfismo sexual (Sick 2001).

Semelhante a outras aves aquáticas, os Ciconiiformes podem ser reservatórios de Salmonella spp, ocorrendo sua infecção por contato com águas poluídas por fezes ou esgotos sem tratamento. A presença dessas aves silvestres próximas a aterros sanitários, zoológicos e parques urbanos pode oferecer riscos de disseminação deste agente (Fontenelle 2006).

\section{HISTÓRICO E TAXONOMIA DE Salmonella SPP.}

As primeiras descrições de bactérias do gênero SalmoneIla spp. datam de 1880, quando Erberth reconheceu o que hoje se denomina Salmonella Typhi como agente patogênico para humanos. Em 1885, Smith e Salmon descreveram o gênero Salmonella após isolarem, o que na época chamaram de Bacillus cholera suis, de suínos com os mesmos sinais clínicos gastroentéricos descritos em humanos por Eberth. Em 1888, Gärtner isolou agentes parecidos de casos de Doenças Transmitidas por Alimentos, mas só em 1900 Lignières classificou o gênero como Salmonella spp (Le Minor 1986).

Desde então, vários autores têm sugerido diferentes formas de classificação das salmonelas, porém o padrão mais aceito na atualidade e visivelmente mais utilizado nos trabalhos publicados é o proposto por Kauffmann-White e adotado pela Organização Mundial da Saúde (OMS), que denominou duas espécies, a Salmonella bongorie Salmonella enterica, sendo esta última dividida em seis subespécies: enterica, salamae, arizonae, diarizonae, houtenae e indica, sendo as demais classificadas como sorovares, num total de 2.489 sorovares (Popoff et al. 2000). A Salmonella bongori foi considerada uma espécie diferente apenas em estudos recentes, e tem poucos sorovares, normalmente não causando doença em humanos, sendo mais associada a doenças em animais de sangue frio (Popoff et al. 2000, Chan et al. 2003).

A subespécie enterica possui a grande maioria dos sorovares (Popoff et al. 2000). Estes sorovares são determinados pela combinação de antígenos de superfície bacteriana $(\mathrm{O}=$ somáticos, $\mathrm{H}$ = flagelares e $\mathrm{Vi}=$ capsulares $)$ (Le Minor 1986). Sendo assim, a forma correta utilizada atualmente para descrever esta bactéria baseia-se no seguinte exemplo: Salmonella enterica subespécie enterica sorovar Enteritidis. Porém, encontra-se comumente nos artigos científicos a abreviação da nomenclatura citando apenas o gênero e o sorovar, como por exemplo, Samonella Enteritidis (Carvalho 2006).

\section{CARACTERÍSTICAS DO AGENTE ETIOLÓGICO}

As bactérias do gênero Salmonella são bacilos Gram negativos, pertencentes à família Enterobacteriaceae, não formadores de esporos, anaeróbios facultativos, que produzem gás sulfídrico $\left(\mathrm{H}_{2} \mathrm{~S}\right)$ a partir da fermentação da glicose (exceto $S$.
Typhi), não fermentadores de lactose, gerando reações alcalinas em ágar Tríplice Açúcar Ferro (TSI). São capazes de utilizar o citrato como única fonte de carbono no meio Citrato de Simmmons. A maioria das Salmonella é móvel por flagelos peritríquios, à exceção da $S$. Pullorum e da $S$. Gallinarum, que são imóveis, apresentando provas de motilidade positivas em meio SIM e geralmente não são produtoras de Indol. Geralmente não produzem urease, apresentando testes em Caldo Uréia negativo, além de apresentarem testes de ágar Lisina Ferro (LIA) positivos, por descarbolxilação da Lisina. A temperatura ótima de crescimento é em média de $38^{\circ} \mathrm{C}$, sendo destruídas a temperaturas acima dos $60^{\circ} \mathrm{C}$, e não apresentando crescimento sob temperaturas abaixo de $5^{\circ} \mathrm{C}$. A atividade de água mínima é de 0,93 a 0,96 e cresce com pH entre 4,5 e 8,0, sendo o ótimo entre 6,0 e 7,5 (Fortuna e Franco 2005, Brasil 2002, Hirsh 2003).

Estas bactérias colonizam o trato digestório de répteis, aves e mamíferos, incluindo o homem (Carvalho 2006, Tessari et al. 2008), e são comumente envolvidas em casos de gastrenterites e outros tipos de infecções, como febre tifóide, meningites, cistites no Brasil e no mundo (Peresi et al. 1998, Millán et al. 2004, Nadvorny et al. 2004, Fortuna e Franco 2005, Carvalho 2006). Em animais, também são citadas como causadoras de enfermidades com manifestações diversas desde gastroentéricas até septicêmicas, em praticamente todas as classes (Gopee et al. 2000, Phalen et al. 2005, Carvalho 2006).

As células bacterianas costumam aderir-se ao epitélio intestinal e invadi-lo, desencadeando processo inflamatório com liberação de polimorfonucleares e macrófagos que fagocitam as bactérias, favorecendo sua disseminação para outros pontos do organismo, bem como resistência a antibióticoterapias, uma vez que elas se multiplicam nestas células de defesa. Essa reação inflamatória também estimula a secreção de íons e água por eliminação de prostaglandinas, levando aos quadros diarréicos característicos, que podem ser sanguinolentos devido à formação de trombos e lesões epiteliais em casos mais avançados da doença (Carvalho 2006).

Vários plasmídeos foram associados à virulência em salmonela, sendo o mais notável deles um da família de grandes plasmídeos, denominados Plasmídeos de Virulência de Salmonella (plasmídeos Spv), com aproximadamente 50 a 100 Kilobases, encontrados nas espécies de Salmonella spp com potencial para produzir doença disseminada. Outros genes são associados a outras características como o Gene Regulador Transicional (SlyA - Salmolisina), que é responsável pela sobrevivência do agente no interior de macrófagos, e o gene Produtos do Promotor ( $p h o P / p h o Q)$, que aparentam ser responsáveis pela resistência as Salmonella às defensinas das células fagocíticas (Hirsh 2003).

Para a população humana, as espécies mais importantes são as causadoras das febres tifóides (S. Typhi) e paratifóide (S. Paratyphi tipos A e C) (Acha e Szyfres, 1986, Fortuna e Franco 2005). Contudo, os outros sorovares podem estar envolvidos em surtos de gastroenterites menos 
graves (aquelas de curso mais rápido causadas por microorganismos menos virulentos), especialmente quando envolvendo alimentos à base de carne e subprodutos aviários (Hoszowsky e Wasyl 2002, Millán et al. 2004, Fortuna e Franco 2005, Carvalho 2006, Tessari et al. 2008).

Os animais domésticos e silvestres são susceptíveis às salmoneloses podendo ser acometidos por qualquer sorovar (Hirsh 2003). Para a avicultura, os sorovares mais importantes são Gallinarum, Pullorum, Tiphymurium e Enteritidis (Buchala et al. 2006), sendo os dois primeiros causadores de infecções mais graves e de maiores perdas econômicas para a avicultura, e os dois últimos sorovares importantes para a saúde pública (Acha e Szyfres 1986). Entretanto, em aves silvestres, a salmonelose (independente do sorovar do agente etiológico envolvido) pode ser uma ameaça à conservação da diversidade biológica, acarretando grande ameaça à avifauna (Carvalho 2006, HernandezDivers et al. 2006, Pennycott et al. 2006, Newman et al. 2007); embora alguns autores enfatizem que na maioria dos casos as aves sejam portadoras sadias (Savidge et al. 1992, Smith et al. 2002, León-Quinto et al. 2004).

\section{CADEIA EPIDEMIOLÓGICA}

A salmonelose pode acometer animais domésticos, silvestres e humanos (Gopee et al. 2000, Kanashiro et al. 2002, Smith et al. 2002, Carvalho 2006) e sua forma de transmissão mais comum é pela via fecal-oral que pode ser por meio da ingestão de água ou alimentos contaminados (Acha \& Szyfres 1886, Smith et al. 2002) ou por contato direto com animais infectados. Outras vias de transmissão também foram relatadas como, por exemplo, o contato com superfícies contaminadas com matéria orgânica, ou com solos úmidos, água, fezes onde o agente pode sobreviver por longos períodos (Carvalho 2006). Petney et al. (2004) descreveram o carrapato Argas persicus como provável vetor mecânico de $S$. Pullorum e $S$. Gallinarum, corroborando com Fortuna e Franco (2005) que citaram o controle de insetos como forma de prevenção, sugerindo que os mesmos possam ser carreadores destas bactérias.

Segundo Hall \& Saito (2008), a ocorrência de surtos de salmonelose depende de variáveis como suscetibilidade da espécie hospedeira, idade do hospedeiro, estresse e virulência do sorovar ou da cepa. Já, Smith et al. (2002) relacionaram que a prevalência de Salmonella spp. em populações de animais silvestres é desconhecida e provavelmente variável. Millán et al. (2004) citaram as aves silvestres como tendo um papel importante na cadeira epidemiológica da doença, sendo algumas delas bastantes suscetíveis à morte por salmonelose como é o caso de pequenos Passeriformes. Estes mesmos autores enfatizaram que evidências epidemiológicas e bacteriológicas indicaram que estes animais podem transmitir a bactéria para humanos e animais de produção. Da mesma forma Bada-Alambedji et al. (2006) sugeriram o contato com aves de vida livre como responsável pela contaminação de carcaças de frango em Dakar, Senegal.

A situação inversa também foi verificada, cujos autores responsabilizaram o homem e seus animais domésticos de criação como responsáveis por disseminação deste patógeno para a fauna silvestre (Gopee et al. 2000, HernandezDivers et al. 2006, Pennycott et al. 2006, Newman et al. 2007), sugerindo a possibilidade de haver um elo entre as cadeias epidemiológicas domésticas e silvestres da salmonelose, além de outras enfermidades bacterianas.

Investigações sobre estas duas assertivas devem ser conduzidas no Brasil, uma vez que o país ocupa posição de destaque no mercado mundial de exportação de carne de frango in natura (Fortuna \& Franco 2005) e também possui uma das maiores diversidades biológicas de aves silvestres do mundo (Sick 2001).

Quanto ao papel dos Ciconiiformes na cadeia epidemiológica da salmonelose, Yorio \& Giaccardi (2002) destacaram os urubus-de-cabeça-preta como responsáveis pela disseminação de Salmonella spp. e outras ameaças à saúde humana, além de citarem a alimentação a partir de detritos humanos como via de transmissão para os Ciconiiformes e outros tipos de aves.

Da mesma forma, isolamentos de sorovares diversos de Salmonella spp. em Ciconiiformes foram obtidos por vários autores. Locke et al. (1974) isolaram Salmonella Typhimurium de ardeídeos de uma colônia mista mantida em cativeiro nos Estados Unidos da América (EUA). Kirkpatrick (1996) relatou o isolamento de S. Newport e S. Copenhagen, em fezes de socós-dorminhocos e caraúnas (Plegadis falcinellus) de vida livre em Nova Jersey, EUA. León-Quinto et al. (2004) relataram mortes por Salmonella Enteritidis em ardeídeos e outras aves no Parque Nacional de El Hondo na Espanha. Grant \& Watson (1995) e Phalen et al. (2005) isolaram Salmonella spp. de garçasvaqueiras em Oklahoma e no Texas, EUA, respectivamente. Em Valencia, Espanha, Navarro et al. (2005) associaram o fato do difícil encontro de helmintos em ardeídeos de diversas espécies ao sinal clínico de diarréia devido à infecção concomitante por Salmonella spp.

Considerando as características epidemiológicas, os hábitos alimentares podem influenciar positivamente na infecção e eventualmente no desenvolvimento de doença ou até na morte de Ciconiiformes e outras aves aquáticas por Salmonella spp. (Newman et al. 2007). Também, as ações antrópicas sobre os ecossistemas aquáticos pela contaminação de cursos d'água com agentes infecciosos (entre eles Salmonella spp.) e poluentes crônicos também estão associados à morte de aves suscetíveis e esta mortalidade pode ser um bioindicador da saúde do ecossistema (Newman et al. 2007).

A proximidade de aves, principalmente garças-vaqueiras, às criações de animais domésticos como ruminantes e equinos, e em ambientes modificados pelo homem (Gopee et al. 2000, Della Bella \& Azevedo-Júnior 2004, Fontenelle 2006) pode representar um risco de infecção para humanos e animais domésticos de criação, corroborando com Millán et al. (2004) e Bada-Alambedji et al. (2006). Tais fatos levam a crer que os Ciconiiformes podem ter um papel importante na epidemiologia das salmoneloses em seus ciclos silvestres. 


\section{MÉTODOS DE DIAGNÓSTICO}

Os principais métodos laboratoriais de diagnóstico da salmonelose são: o isolamento do agente (exames microbiológicos), exame sorológico, técnicas de biologia molecular, além do diagnóstico clínico a partir dos sinais (Hirsh 2003, Carvalho 2006). Amostras de fezes podem ser colhidas em swabs em casos de infecção intestinal e amostras de sangue em casos de infecção sistêmica. Pode-se também cultivar o baço e a medula óssea para diagnóstico post mortem de salmonelose sistêmica (Hirsh 2003).

A cultura bacteriológica é o método de escolha para isolamento deste agente. O protocolo utilizado envolve pré-enriquecimento; enriquecimento seletivo e cultivo em no mínimo dois meios de cultivo seletivos para enterobactérias; testes bioquímicos para confirmação do gênero nas colônias suspeitas; e testes de caracterização antigênica através de soroaglutinação rápida para confirmação do sorovar (Le Minor 1986, Hirsh 2003). Trabalhos realizados no Brasil (Kanashiro et al. 2002, Tessari et al. 2008), normalmente adotaram os protocolos indicados pelo Programa Nacional de Sanidade Avícola (PNSA) do Ministério da Agricultura, Pecuária e Abastecimento (MAPA) com os meios de cultivo (Brasil 2002):

Nos trabalhos internacionais analisados utilizaram-se os meios de cultivo indicados pelo PNSA (Brasil 2002), havendo apenas variação de uso de alguns meios não inclusos neste programa, como Ágar Salmonella-Shigella, Ágar Sangue ou Ágar MacConkey (Smith et al. 2002, Rojas et al. 2002, Millán et al. 2004, Phalen et al. 2005, Bada-Alambedji et al. 2006). Isto sugere um reconhecimento mundial desses meios como prioritários para isolamento dessas enterobactérias.

Considerando os diagnósticos sorológicos eles geralmente são realizados em pacientes humanos com salmoneloses severas. Este diagnóstico é pouco preciso, uma vez que a grande variedade de sorovares pode dificultar o diagnóstico, pois normalmente estão mais disponíveis aglutininas para os sorovares Typhi, Paratyphi A e B e eventualmente Paratyphi C. Além disso, reações cruzadas com sorovares que tenham antígenos parecidos podem ocorrer (Le Minor 1986). Este tipo de diagnóstico é pouco recomendado para aves silvestres.

Outro recurso diagnóstico que pode ser utilizado é a biologia molecular. Padilla et al. (2004) citaram o uso da Reação em Cadeia da Polimerase (PCR) para testar a presença ou ausência de Salmonella em aves silvestres de Galápagos, porém os resultados não indicaram os sorovares, confirmando apenas o gênero. Outro trabalho citou o uso de PFGE (Pulse-filed Gel Electrophoresis) para obter informações sobre sorovares de Salmonella spp, porém para a confirmação do agente se deu por cultivo bacteriano (Old et al. 1999).

Quanto ao diagnóstico clínico, o mesmo deve ser feito baseado nos sinais da doença que variam de acordo com a espécie animal acometida, do sorovar envolvido, da suscetibilidade individual do paciente, do tamanho do inoculo e de fatores estressantes. De maneira geral pode haver infecções subclínicas, processos entéricos e até septicemias. Em mamíferos, processos crônicos podem causar abortamentos e diminuição da fertilidade e da produção de leite. Em aves pode haver diminuição na postura de ovos ou na taxa de eclosão destes, além de ingluvites, poliartrites e dermatites granulomatosas nos processos crônicos. Nos répteis com salmonelose crônica podem-se observar abscessos e lesões granulomatosas em tecidos diversos. Já nos casos mais agudos, na maioria das espécies, ocorre diarréia com cólicas, podendo chegar a diarréias sanguinolentas nos casos mais graves, bem como processos inflamatórios generalizados causando meningites, artrites sépticas e pneumonias. Contudo, a confirmação deve ser feita por meio de isolamento bacteriano (Carvalho 2006).

\section{TRATAMENTO}

Terapia de suporte é o principal tratamento para a forma entérica da salmonelose (Hirsh 2003, Carvalho 2006). O uso de antibióticos para o tratamento é controverso, devendo ficar restrito a casos de doença grave, devido à ampla resistência a antimicrobianos, especialmente às quinolonas, cefalosporinas de última geração, ampicilina e gentamicina (Carvalho 2006). Outros autores também relataram casos de multiresistência de Samonella spp (Gopee et al. 2000, Hoszoswsky \& Wasyl 2002, Kanashiro et al. 2002, Fortuna \& Franco 2005). Mesmo assim, os principais fármacos indicados ao tratamento das salmoneloses aviárias são araparcina, lincomicina, furazolidona, estreptomicina e gentamicina. Uma possível explicação para fenômeno de multiresistência, é o uso indiscriminado de antibióticos em tratamento de humanos e animais, além de seu uso em rações animais, que atualmente encontra-se proibido no Brasil, porém já foi amplamente utilizado (Le Minor 1986, Gopee et al. 2000, Kanashiro et al. 2002, Fortuna e Franco 2005, Bada-Alambedji et al. 2006). O uso de probióticos nas rações tem demonstrado sucessos para reduzir o número de salmonelas eliminadas por aves portadoras (Hirsh 2003). Alguns autores apontaram mutações genéticas do agente como responsáveis pela multiresistência a antimicrobianos (Havlickova et al. 2009) e a capacidade de mutação de Salmonella enterica sorovar Typhimurium de acordo com a espécie animal (Malcova et al. 2008).

\section{IMPLICAČ̃ES PARA A SAÚDE PÚBLICA E A CONSERVAÇÃO DA DIVERSIDADE BIOLÓGICA}

Em aves de produção, Bada-Alambedji et al. (2006) apontaram o contato com aves silvestres externas às granjas produtoras como provável via de transmissão de salmonelose, sendo totalmente compatível com os relatos de DeVault et al. (2003) e Della Bella \& Azevedo-Júnior (2004), quando estes descreveram os hábitos de diversas espécies de Ciconiiformes de se tornarem sinantrópicas. Yorio \& Giaccardi (2002) verificaram os Ciconiiformes como possíveis disseminadores de salmoneloses para populações humanas e de animais de criação. Esta possível exposição ao agente pode infectar as aves, suas carcaças ou ovos podendo representar um risco para os humanos.

Conforme citado anteriormente, outra importante via de transmissão de salmonelas é a água. Nos ambientes aquáticos (açudes, reservatórios, córregos, riachos, entre ou- 
tros), seu uso por ardeídeos pode promover a contaminação da água e disseminar este patógeno para populações humanas e de animais domésticos e silvestres (Gopee et al. 2000, Fortuna \& Franco 2005, Newman et al. 2007). Do mesmo modo vegetais irrigados com esta água contaminada podem também ser fontes de infecção (Fortuna \& Franco 2005).

Ainda com relação à saúde pública, parques zoológicos e criadouros podem proporcionar a infecção cruzada de salmonelas entre visitantes e os animais silvestres cativos (Gopee et al. 2000). Carvalho (2006) ressaltou a importância de se ter locais para lavagem das mãos em parques zoológicos onde há contato físico dos visitantes com os animais, para que se evitem zoonoses como as salmoneloses.

No tocante à conservação da diversidade biológica, as aves silvestres geralmente atuam como reservatórias e portadoras da salmonelose (Carvalho 2006) sendo pouco frequentes os casos clínicos (Savidge et al. 1992). Mesmo assim, os Passeriformes (Pennycott et al. 2006) e aves marinhas (Newman et al. 2007) podem ser suscetíveis ao óbito por salmoneloses. Estes óbitos foram relacionados à ingestão de restos de alimentos humanos por Passeriformes (Pennycott et al. 2006) e de água contaminada por dejetos humanos por aves marinhas (Newman et al. 2007). Em um estudo realizado no Nordeste do Equador, Hernandez-Divers et al. (2006) apontaram as criações de aves domésticas como uma possível fonte de infecção para aves sinantrópicas (incluindo urubus e garças). Estas aves silvestres infectadas então podem disseminar patógenos como a Salmonella spp. para populações de outras aves silvestres.

Contudo, no Brasil, a garça-vaqueira (Bubulcus ibis) é um dos ardeídeos que podem representar um risco de transmissão de salmonelas. Nos últimos anos tem sido verificado um aumento populacional desta ave no continente (Della Bella \& Azevedo-Júnior 2004) e em Fernando de Noronha (Alves 2007, Cemave 2008). É comum verificálas forrageando perto do gado e de eqüinos para alimentarse de insetos encontrados nos pastos (Della Bella \& Azevedo-Júnior 2004), próximas de galpões de frangos de corte e de postura, e em açudes e outros ambientes aquáticos para se alimentarem.

Por fim, conforme mencionado, as enfermidades infecciosas podem atuar no declínio de populações de animais silvestres, sendo uma ameaça à conservação da diversidade biológica (Andriolo 2006, Hernandez-Divers et al. 2006). Pelo difícil êxito no tratamento da salmonelose (Carvalho 2006), os Ciconiiformes serem possíveis agentes disseminadores das salmonelas (Yorio \& Giaccardi 2002) para fauna silvestre de vida livre (Henandez-Divers et al. 2006) e de cativeiro (Gopee et al. 2000) e algumas aves silvestres serem susceptíveis à morte por salmonelose (Locke et al. 1974), maiores investigações epidemiológicas são necessárias para um melhor entendimento dos elos da cadeia de transmissão da salmonelose. Também, a associação entre a ocorrência da Salmonella spp. e aves da Ordem Ciconiiformes pode estar sendo subestimada necessitando mais pesquisas.

\section{PREVENÇÃO E CONTROLE}

As medidas de biossegurança nas criações de animais silvestres em cativeiro são as mais indicadas na prevenção e controle da salmonelose. A implantação de normas rígidas e de Procedimentos Operacionais Padronizados (POP) deve ser realizada na forma de manuais e serem seguidos pelo corpo técnico e estagiários destes estabelecimentos. Deve-se sempre ficar atento à higiene e desinfecção dos recintos com hipoclorito de sódio, bem como cuidados com o bem-estar animal (Carvalho 2006).

As aves silvestres recém adquiridas nos parques zoológicos, criadouros e Centros de Triagem de Animais Silvestres (CETAS) devem ficar em quarentena. Se possível, as aves devem ser mantidas isoladas para observação em três semanas, fazendo-se neste espaço de tempo três exames bacteriológicos das fezes para pesquisa de salmonelas, a fim de evidenciar portadores, evitando-se futuros casos de doença e uma possível disseminação para outros animais silvestres e o homem (Giorgi 1973).

Em cativeiro, as principais aves da Ordem Ciconiiformes são garças, socós, colhereiros, maguaris, guarás e jaburus, que são alojadas em grupos em recintos telados com presença de tanques de água, bandejas de alimentos e bebedouros geralmente dispostos no chão (Fontenelle 2006). Estas características físicas dos recintos proporcionam um possível contato principalmente com fezes de animais sinantrópicos (roedores e aves) que podem atuar como fontes de infecção da salmonelose para as aves cativas. Desta forma, deve-se evitar a construção de ninhais de garças e socós em cima dos recintos e evitar o contato das aves de zoológicos com animais sinantrópicos, não permitindo sua entrada nos recintos. Outra medida é o monitoramento no trânsito de pessoal entre os recintos de aves silvestres que podem carrear salmonelas pela matéria orgânica presente nos calçados (Silva \& Corrêa 2006).

Outro foco baseia-se na segurança alimentar que é essencial no controle e prevenção de salmonelose em coleções de animais silvestres. Esta deve ser feita pelo controle de qualidade dos alimentos, em especial os de origem animal (Carvalho 2006). Desta forma, a higiene dos manipuladores na preparação das bandejas dos alimentos dos animais silvestres de parques zoológicos e criadouros é de fundamental importância para se evitar a sua infecção pela ingestão de água e alimentos contaminados por salmonelas (Giorgi 1973, Carvalho 2006). Também, o uso de probióticos nas rações pode auxiliar na prevenção desta zoonose (Carvalho 2006).

De acordo com a exposição das aves sinantrópicas com aves de produção, deve-se evitar o contato de garças, socós, urubus e outros Ciconiiformes em galpões de frangos de corte e de postura. Medidas como redução de sítios de nidificação, gestão adequada de resíduos, uso de falcoaria, além de modificações estruturais como alteração no tipo de cobertura vegetal e disponibilidade de água, podem ser adaptadas de outras formas de redução da população de aves, como em zonas aeroportuárias (Serrano et al. 2005). Estes autores relataram ainda a importância 
do monitoramento comportamental das aves sinantrópicas para que seja assegurada a eficácia dos métodos utilizados e alternação entre eles quando se fizer necessário. Tais medidas podem ser adequadas se adaptadas à realidade das criações comerciais de animais de produção.

Considerando a importância da prevenção e o controle para aves silvestres de vida livre no tocante a infecção por Salmonella e das salmoneloses aviárias algumas medidas de prevenção e controle podem ser implementadas, tais como: (a) Melhoria do saneamento básico evitando o destino de esgotos de origem humana ou de animais de produção em rios, lagos, açudes, praias, oceanos ou outras coleções líquidas. As aves Ciconiiformes forrageiam e se alimentam próximos de cursos d'água e assim podem se infectar com as salmonelas e tornarem-se fontes de infecção; e (b) Melhoria do destino de resíduos sólidos de áreas urbanas e rurais, por meio de uma melhoria da coleta seletiva de lixo e construções de aterros sanitários, evitando o depósito e acúmulo em lixões.

Estas ações são de cunho geral, mas podem ser implantadas por meio de exceções de leis municipais, estaduais e federais pelo uso de políticas públicas. Não podemos dissociar a questão do saneamento básico, destino de resíduos com a conservação da vida silvestre. Principalmente relacionado à possível disseminação de patógenos de importância na saúde animal e pública. As salmonelas são um importante exemplo nesta interface dos problemas ambientais de poluição antrópicos e o seu impacto na fauna silvestre.

Finalizando, a educação em saúde é uma essencial ferramenta para tratadores, técnicos, estagiários e do público visitante (Silva \& Corrêa 2006) em zoológicos e criadores ou em ações de saúde pública e de conservação do meio ambiente. A elaboração de cartilhas, folhetos e vídeos educativos podem ser de extrema valia para a conquista de resultados satisfatórios visando a vigilância e a promoção de saúde.

\section{CONSIDERAÇÕES FINAIS}

Diante do exposto, por meio da literatura pesquisada, podese perceber uma relevante importância das aves Ciconiiformes como um elo entre a população humana e seus animais de criação às populações de animais silvestres, carreando sorovares diversos de Salmonella spp. ou sendo infectada por este agente. A adaptabilidade dessas aves Ciconiiformes ao ambiente antrópico facilita a cadeia de transmissão da salmonelose. Um maior número de estudos, especialmente correlacionando isolamentos de Salmonella spp. em Ciconiiformes sinantrópicos e animais de produção, animais silvestres cativos, ou ainda em populações humanas, que possam comprovar esta hipótese, podem se fazer necessários. Tal atitude pode promover melhorias nas formas de promoção da saúde pública e ambiental, conservação da diversidade biológica e uso sustentável de recursos naturais, contribuindo ainda mais para uma convivência harmônica entre o homem e o restante das espécies animais habitantes do Planeta Terra.
Agradecimentos.- À Coordenação de Aperfeiçoamento de Pessoal de Nível Superior (CAPES), pela concessão de bolsa de mestrado, e ao Conselho Nacional de Desenvolvimento Científico e Tecnológico (CNPq).

\section{REFERÊNCIAS}

Acha P.N. \& Szyfres B. 1986. Salmonelosis, p.158-167. In: Ibid. (Eds), Zoonosis y Enfermedades Transmisibles Comunes al Hombre y a los Animales. Organización Panamericana de La Salud, Washington.

Alves M.L. 2007. Plano de manejo visando evitar e/ou reduzir colisões com a fauna silvestre do SBFN. Fernando de Noronha: Administração Aeroportuária do SBFN. Fernando de Noronha, PE. 37p. (Relatório)

Andriolo A. 2006. Desafios para a conservação da fauna, p19-25. In: Cubas Z.S., Silva J.C.R. \& Catão-Dias J.L. (Eds), Tratado de Animais Selvagens: medicina veterinária. Roca, São Paulo.

Bada-Alambedji R., Fofana A., Seydi M. \& Akakpo A.J. 2006. Antimicrobial resistance of Salmonella isolated from poultry carcasses in Dakar (Senegal). Braz. J. Microbiol. 37:510-515.

Brasil 2002. Programa nacional de sanidade avícola. Ministério da Agricultura, Pecuária e Abastecimento, Brasília, DF. 312p.

Buchala F.G., Ishizuka M.M., Mathias L.A., Berchieri Jr A., Castro A.G.M., Cardoso A.L.S.P., Tessari E.N.C. \& Kanashiro A.M.I. 2006. Ocorrência de reação sorológica contra Salmonella Pullorum em aves de "fundo de quintal" no estado de São Paulo, Brasil. Arqs Inst. Biológico, São Paulo, 73:1-5.

Cambre R.C., Green D.E., Smith E.E., Montali R.J. \& Bush M. 1980. Salmonellosis and Arizonosis in the reptile collection of the National Zoological Park. J. Am. Vet. Med. Assoc. 177:800-803.

Carvalho V.M. 2006. Colibacilose e salmonelose, p.742-750. In: Cubas Z.S., Silva J.C.R. \& Catão-Dias J.L. (Eds), Tratado de Animais Selvagens: medicina veterinária. Roca, São Paulo.

Cemave 2008. Relatório técnico da expedição do projeto "monitoramento de Bubulcus ibis no Parque Nacional Marinho e na Área de Proteção Ambiental de Fernando de Noronha", de 22 a 30 de abril de 2008. Centro Nacional de Pesquisa para Conservação das Aves Silvestres (CEMAVE): Instituto Chico Mendes de Conservação da Biodiversidade (ICMBio), Cabedelo, CE. 33p. (Relatório)

Chan K., Baker S., Kim C.C., Detweiler C.S., Dougan G. \& Falkow S. 2003. Genomic comparison of Salmonella enterica serovars and Salmonella bongori by use of a $S$. enterica serovar Tiphymurium DNA microarray. J. Bacteriol. 185:533-563.

Della Bella S. \& Azevedo-Júnior S.M. 2004. Considerações sobre a ocorrência da garça-vaqueira, Bubulcus ibis (Linnaeus) (Aves, Ardeidae), em Pernambuco, Brasil. Revta Bras. Zool. 21:57-63.

DeVault T.L., Rhodes O.E. \& Shivik J.A. 2003. Scavenging by vertebrates: Behavioral, ecological, and evolutionary perspectives on an important energy transfer pathway in terrestrial ecosystems. Oikos 102:225-234.

Fontenelle J.H. 2006. Ciconiiformes, p.290-300. In: Cubas Z.S., Silva J.C.R. \& Catão-Dias J.L. (Eds), Tratado de Animais Selvagens: medicina veterinária. Roca, São Paulo.

Fortuna J.L. \& Franco R.B. 2005. Pequeno dossiê epidemiológico da Salmonella, como causadora de infecções alimentares. Hig. Alim. 128:33-43.

Giorgi W. 1973. Infecções por salmonelas em animais do parque zoológico de São Paulo. Arqs Inst. Biológico, São Paulo, 40:1-3.

Grant K.R. \& Watson J. 1995. Controlling nuisance egret and heron rookeries in Oklahoma. Proc. $12^{\text {th }}$ Great Plains Wildlife Damage Control Workshop, University of Nebraska, Lincoln, p.32-33.

Gopee N.V., Adesiyun A.A. \& Caesar K. 2000. Retrospective and longitudinal study of salmonellosis in captive wildlife in Trinidad. J. Wild. Dis. 36:284-293.

Hall A.J. \& Saito E.K. 2008. Avian wildlife mortality events due to salmonellosis in the United States, 1985-2004. J. Wild. Dis. 44:585-593. 
Havlickova H., Hradecka H., Bernardyova I. \& Richlik I. 2009. Distribution of integrons and SGI1 among antibiotic-resistant Salmonella enterica isolates of animal origin. Vet. Microbiol. 133:193-198.

Hernandez-Divers S.M., Villegas P., Prieto F., Unda J.C., Stedman N., Ritchie B., Carroll R. \& Hernandez-Divers S.J. 2006. A survey of selected avian pathogens of backyard poultry in Northwestern Ecuador. J. Avian Med. Surg. 20:147-158.

Hirsh D.C. 2003. Salmonella, p.69-73. In: Hirsh D.C. \& Zee Y.C. (Eds), Microbiologia Veterinária. Guanabara Koogan, Rio de Janeiro.

Hoszoswsky A. \& Wasyl D. 2002. Salmonella serovars found in animals and feeding stuffs in 2001 and their antimicrobial resistence. Bull. Vet. Inst. Pulawy 46:165-178.

Kanashiro A.M.I., Castro A.G.M., Cardoso A.L.S.P., Tessari E.N.C. \& Tavechio A.T. 2002. Persistência de Salmonella sp após antibioticoterapia em psitacídeos pertencentes a um criadouro comercial. Arqs Inst. Biológico, São Paulo, 69:99-101.

Kirkpatrick C.E. 1996. Isolation of Salmonella spp. from a colony of wading birds. J. Wild. Dis. 22:262-264.

Le Minor L. 1986. The genus Salmonella, p.1148-1159. In: Starr M.P., Stolp H., Trüper H.G., Balows A. \& Schlegel H.G. (Eds), The Prokaryotes: A handbook on habitats, isolation, and identification of bacteria. Vol.2. $2^{\text {nd }}$ ed. Springer-Verlag, Berlin.

León-Quinto T., De La Vega A., Lozano A. \& Pastor S. 2004. Summer mortality of waterbirds in a Mediterranean wetland. Waterbirds 27:4653.

Locke L.N., Ohlendorf H.M., Shillinger R.B. \& Jareed T. 1974. Salmonellosis in a captive heron colony. J. Wild. Dis. 10:143-145.

Millán J., Aduriz G., Moreno B., Juste R.A. \& Barral M. 2004. SalmoneIla isolates from wild birds and mammals in the Basque Country (Spain). Rev. Sci. Tech. Off. Int. Epiz. 23:905-911.

Malcova M., Hradecka H., Karpiskova R. \& Rychlik I. 2008. Biofilm formation in field strains of Salmonella enterica serovar Typhimurium: Identification of a new colony morphology type and the role of SGI1 in biofilm formation. Vet. Microbiol. 129:360-366.

Navarro P., Lluch J. \& Font E. 2005. The component helminth community in six sympatric species of Ardeidae. J. Parasitol. 91:775-779.

Nadvorny A., Figueiredo D.M.S. \& Schmidt V. 2004. Ocorrência de Salmonella sp. em surtos de doenças transmitidas por alimentos no Rio Grande do Sul em 2000. Acta Sci. Vet. 32:47-51.

Newman S.H., Chmura A., Converse K., Kilpatrick A.M., Patel N., Lammers E. \& Daszak P. 2007. Aquatic bird disease and mortality as an indicator of changing ecosystem health. Mar. Ecol. Prog. Ser. 352:299-309.

Old D.C., Rankin S.C. \& Crichton P.B. 1999. Assessment of strains relatedness among Salmonella serotypes Salinatis, Duisburg, and
Sandiego by biotyping, ribotyping, IS200 fingerprinting, and pulsedfield gel electrophoresis. J. Clin. Microbiol. 37:1687-1692.

Padilla L.R., Santiago-Alarcon D., Merkel J., Miller R.E. \& Parker P.G. 2004. Survey for Haemoproteus spp., Trichomonas gallinae, Chlamydophilla psittaci, and Salmonella spp. in Galapagos Islands columbiformes. J. Zoo Wild. Med. 35:60-64.

Pennycott T.W., Park A. \& Mather H.A. 2006. Isolation of different serovars of Salmonella enterica from wild birds in Great Britain between 1995 and 2003. Vet. Reco. 158:817-820.

Peresi J.T.M., Almeida I.A.Z.C., Lima S.I., Marques D.F., Rodrigues E.C.A., Fernandes S.A., Gelli D.S. \& Irino K. 1998. Surtos de enfermidades transmitidas por alimentos causados por Salmonella Enteritidis. Revta Saúde Pública 32:477-483.

Petney T.N., Andrews R.H., McDiarmid L.A. \& Dixon B.R. 2004. Argas persicus sensu stricto does occur in Australia. Parsitol. Res. 93:296-299.

Phalen D.N., Drew M.L., Contreras C., Roset K. \& Mora M. 2005. Naturally occurring secondary nutritional hyperparathyroidism in cattle egrets (Bubulcus ibis) from central Texas. J. Wild. Dis. 41:401-415.

Popoff M.Y., Bockemuhl J. \& Brenner F.W. 2000. Supplement 1999 (no.43) to the Kauffmann-White scheme. Res. Microbiol. 151:893-896.

Rojas M.J., Rejo M.G.T., Masdeu V. \& Acosta I. 2002. Hallazgos bacteriológicos y micológicos en aves psitácidas. Revta Cubana Ciênc. Avíc. 26:125-128.

Savidge J.A., Sileo L. \& Siegfried L.M. 1992. Was disease involved in the decimation of Guam's avifauna? J. Wild. Dis. 28:206-214.

Serrano I.L., Schulz Neto A., Alves V.S., Maia M., Efe M.A., Telino Júnior W.R. \& Amaral M.F. 2005. Diagnóstico da situação nacional de colisões de aves com aeronaves. Ornithol. 1:93-104

Sick H. 2001. Ornitologia Brasileira. Nova Fronteira, Rio de Janeiro. 914p.

Silva J.C.R. \& Corrêa S.H.R. 2006. Manejo sanitário e biosseguridade, p.1226-1244. In: Cubas Z.S., Silva J.C.R. \& Catão-Dias J.L. (Eds), Tratado de Animais Selvagens: medicina veterinária. Roca, São Paulo.

Smith W.A., Mazet J.A.K. \& Hirsh D.C. 2002. Salmonella in California wildlife species: Prevalence in rehabilitation centers and characterization of isolates. J. Zoo Wild. Med. 33:228-235.

Tessari E.N.C., Cardoso A.L.S.P., Kanashiro A.M.I., Stoppa G.F.Z., Luciano R.L. \& Castro A.G.M. 2008. Ocorrência de Salmonella spp. em carcaças de frangos industrialmente processadas, procedentes de explorações industriais do Estado de São Paulo, Brasil. Ciência Rural 38:10-16.

Yorio P. \& Giaccardi M. 2002. Urban and fishery waste tips as food sources for birds in northern coastal Patagonia, Argentina. Ornitol. Neotrop. 13:283-292. 